\title{
Perioperative imaging in patients treated with resection of brain metastases: a survey by the European Association of Neuro- Oncology (EANO) Youngsters committee
}

Barbara Kiesel ${ }^{1,2}$, Carina M. Thomé3 ${ }^{3}$, Tobias Weiss ${ }^{4}$, Asgeir S. Jakola ${ }^{5}$, Amélie Darlix $^{6}$, Alessia Pellerino ${ }^{7}$, Julia Furtner ${ }^{2,8}$, Johannes Kerschbaumer ${ }^{9}$, Christian F. Freyschlag ${ }^{9}$, Wolfgang Wick ${ }^{3,10}$, Matthias Preusser ${ }^{2,11}$, Georg Widhalm ${ }^{1,2}$ and Anna S. Berghoff', ${ }^{2} 1^{*}$

\begin{abstract}
Background: Neurosurgical resection represents an important treatment option in the modern, multimodal therapy approach of brain metastases (BM). Guidelines for perioperative imaging exist for primary brain tumors to guide postsurgical treatment. Optimal perioperative imaging of BM patients is so far a matter of debate as no structured guidelines exist.

Methods: A comprehensive questionnaire about perioperative imaging was designed by the European Association of Neuro-Oncology (EANO) Youngsters Committee. The survey was distributed to physicians via the EANO network to perform a descriptive overview on the current habits and their variability on perioperative imaging. Chi square test was used for dichotomous variables.

Results: One hundred twenty physicians worldwide responded to the survey. MRI was the preferred preoperative imaging method (93.3\%). Overall 106/120 (88.3\%) physicians performed postsurgical imaging routinely including MRI alone (62/120 [51.7\%]), postoperative CT (29/120 [24.2\%]) and MRI + CT (15/120 [12.5\%]). No correlation of postsurgical MRI utilization in academic vs. non-academic hospitals (58/89 [65.2\%] vs. 19/31 [61.3\%], $p=0.698$ ) was found. Early postoperative MRI within $\leq 72 \mathrm{~h}$ after resection is obtained by $60.8 \%$ of the participants. The most frequent reason for postsurgical imaging was to evaluate the extent of tumor resection (73/120 [60.8\%]). In case of residual tumor, 32/120 (26.7\%) participants indicated to adjust radiotherapy, 34/120 (28.3\%) to consider re-surgery to achieve complete resection and 8/120 (6.7\%) to evaluate both.
\end{abstract}

Conclusions: MRI was the preferred imaging method in the preoperative setting. In the postoperative course, imaging modalities and timing showed high variability. International guidelines for perioperative imaging with special focus on postoperative MRI to assess residual tumor are warranted to optimize standardized management and adjuvant treatment decisions for BM patients.

Keywords: Postoperative MRI, International guidelines, Perioperative imaging, Brain metastases

\footnotetext{
* Correspondence: anna.berghoff@meduniwien.ac.at

${ }^{2}$ Comprehensive Cancer Center, Medical University of Vienna, Vienna, Austria

${ }^{11}$ Department of Medicine I, Clinical Division of Oncology, Medical University of Vienna, Waehringer Guertel 18-20, 1090 Vienna, Austria

Full list of author information is available at the end of the article
}

(c) The Author(s). 2020 Open Access This article is licensed under a Creative Commons Attribution 4.0 International License, which permits use, sharing, adaptation, distribution and reproduction in any medium or format, as long as you give appropriate credit to the original author(s) and the source, provide a link to the Creative Commons licence, and indicate if changes were made. The images or other third party material in this article are included in the article's Creative Commons licence, unless indicated otherwise in a credit line to the material. If material is not included in the article's Creative Commons licence and your intended use is not permitted by statutory regulation or exceeds the permitted use, you will need to obtain permission directly from the copyright holder. To view a copy of this licence, visit http://creativecommons.org/licenses/by/4.0/. The Creative Commons Public Domain Dedication waiver (http://creativecommons.org/publicdomain/zero/1.0/) applies to the data made available in this article, unless otherwise stated in a credit line to the data. 


\section{Background}

Brain metastases (BM) are a major challenge in modern oncology, as the limited treatment options result in high symptomatic burden and poor patient prognosis [1]. Neurosurgical resection represents an important treatment option, especially in patients with solitary BM unknown histology or risk of hydrocephalus [2]. International guidelines from the European Association of Neuro-Oncology (EANO) recommend resection of single, large (diameter $\geq 3 \mathrm{~cm}$ ) and surgically accessible $\mathrm{BM}$, and for patients presenting severe neurological symptoms and good general health [2]. The neurosurgical goal is to achieve complete resection of BM and subsequent postoperative local radiotherapy/stereotactic radiosurgery (SRS) is able to minimize local tumor recurrence risk [2-4]. However, complete neurosurgical resection might be challenging in some cases as not all $\mathrm{BM}$ present with a clear cut, well-demarcated border to the surrounding brain parenchyma $[5,6]$. BM lacking a clear-cut demarcation to the surrounding brain parenchyma are at particular risk of incomplete resection, potentially contributing significantly to the local recurrence rate of up to $30.9 \%$ after neurosurgical resection [7].

Perioperative imaging is routinely applied to improve neurosurgical resection in glioma patients. Preoperative imaging is used to plan and guide surgery to ensure maximal possible extent of resection and early $(<72 \mathrm{~h}$ after resection) postoperative imaging is utilized to identify residual tumor [8-11]. Improved extent of tumor resection has been associated with a longer progression-free survival and overall survival in glioma patients, underscoring the need for optimal tumor resection and the need to address residual tumor formations [11-15].

Computed tomography (CT) scans were shown to be insufficient to differentiate between residual tumor and postoperative bleeding in primary brain tumors, emphasizing the need for postsurgical magnetic resonance imaging (MRI) to guide further treatment options $[8,16]$. In order to harmonize the perioperative imaging and optimally guide the therapy approaches, several international guidelines on glioma treatment include detailed imaging recommendations $[8,16]$. Currently, postoperative MRI within $72 \mathrm{~h}$ is routinely performed at most centers worldwide to investigate the extent of resection after surgery of diffuse infiltrating gliomas [17]. Indeed, postoperative MRI frequently impacts adjuvant treatments as re-resection or adaption of the postoperative treatment can be considered in case of residual tumor $[8,9,18]$.

In contrast, perioperative imaging is not standardized in BM patients as so far, no guidelines advocate optimal imaging procedures. Therefore, we aimed to perform a survey analyzing the routine practice of perioperative imaging in patients with BM among the EANO network, to gain insight on the current common practice and especially the variability throughout centers with academic and non-academic backgrounds as well as high and low patient volume centers.

\section{Methods \\ Study design and targeted population}

A survey addressing the perioperative management of surgically treated BM patients was designed by the EANO Youngsters committee using an online tool (Survey Monkey@ Inc., San Mateo, California, USA, www. surveymonkey.com). The EANO Board members reviewed and approved the survey focus and content. The survey was sent electronically between May and July 2017 to all members of the EANO, and thereby including physicians with a particular focus on neurooncology.

\section{Survey content}

This anonymous survey included 19 questions (10 single and 9 multiple-choice questions) addressing the following topics: general information, perioperative standards, preoperative imaging, intraoperative imaging, applied imaging techniques including MRI, CT and positron emission tomography (PET), postoperative imaging and implementation of a dedicated neuro-oncology tumor board (see supplemental material for the full survey questionnaire). Completion of the entire questionnaire took around 5-10 min.

\section{Statistical analysis}

The aim of the current study was to provide a descriptive overview on the current habits and their variability on perioperative imaging within the EANO network. For statistical purposes countries with 3 or less participants were combined in the category 'others'. High volume centers were defined by a caseload $>50$ treated BM patients per year and low volume centers by a caseload $\leq 50$ BM patients per year. Community hospitals, private hospitals and private practices were combined in the category 'non-academic center' while university hospitals were referred to as 'academic center'. Chi square test was used for dichotomous variables. A two-sided $p$-value $<0.05$ was considered as significant. All analyses were performed using the software SPSS (IBM SPSS Statistics, Version 25.0. Armonk, NY: IBM Corp.).

\section{Results}

Physicians' demographical data

The survey was distributed via the EANO newsletter to 1054 E-mailing addresses. A total of 120 questionnaires from individual physicians were submitted, resulting in a response rate of $11.4 \%$. The majority of participants were 
neurosurgeons (76/120 [63.3\%]), followed by radiation oncologists $(18 / 120 \quad[15 \%])$, neurologists $(17 / 120$ [14.2\%]) and medical oncologists (6/120 [5\%]; see Table 1 and Fig. 1a for details). Among the participating physicians, 93/120 (77.5\%) were from European countries and 27/120 (22.5\%) from non-European countries. The majority of participants $(89 / 120$ [74.2\%]) were located in academic centers, while $31 / 120(25.8 \%)$ were located in non-academic centers (Fig. 1b). 40/120 (33.3\%) physicians worked at high patient volume centers $(>50 \mathrm{BM}$ patient cases per year) and 71/120 (59.2\%) in low patient volume centers ( $\leq 50 \mathrm{BM}$ patient cases per year). Areas

Table 1 Physicians' demographical data

\begin{tabular}{|c|c|c|}
\hline & $\mathrm{n}$ & $\%$ \\
\hline \multicolumn{3}{|l|}{ Specialty } \\
\hline Neurosurgery & 76 & 63.3 \\
\hline Radiation Oncology & 18 & 15.0 \\
\hline Neurology & 17 & 14.2 \\
\hline Medical Oncology & 6 & 5.1 \\
\hline (Neuro)Pathology & 1 & 0.8 \\
\hline Radiology & 1 & 0.8 \\
\hline Not Known & 1 & 0.8 \\
\hline \multicolumn{3}{|l|}{ Country } \\
\hline Germany & 15 & 12.5 \\
\hline Netherlands & 11 & 9.2 \\
\hline United Kingdom & 10 & 8.3 \\
\hline Switzerland & 8 & 6.7 \\
\hline Italy & 7 & 5.8 \\
\hline Belgium & 5 & 4.2 \\
\hline Austria & 4 & 3.3 \\
\hline Brazil & 4 & 3.3 \\
\hline France & 4 & 3.3 \\
\hline Poland & 4 & 3.3 \\
\hline Spain & 4 & 3.3 \\
\hline United States of America & 4 & 3.3 \\
\hline Others & 40 & 33.3 \\
\hline \multicolumn{3}{|l|}{ Type of institution } \\
\hline Academic/University hospital & 89 & 74.2 \\
\hline Community hospital & 15 & 12.5 \\
\hline Private hospital & 14 & 11.7 \\
\hline Private practice & 2 & 1.6 \\
\hline \multicolumn{3}{|l|}{ Number of cases } \\
\hline $\begin{array}{l}\text { Low volume center } \\
\text { ( } \leq 50 \text { cases per year) }\end{array}$ & 71 & 59.2 \\
\hline $\begin{array}{l}\text { High volume center } \\
\text { (> } 50 \text { cases per year) }\end{array}$ & 40 & 33.3 \\
\hline None & 4 & 3.3 \\
\hline Not known & 5 & 4.2 \\
\hline
\end{tabular}

of specialization were evenly distributed within academic center type (see Fig. 1b and supplementary Table 1 for details). Further, no difference regarding specialties according to patient volume center or center localization was observed (see Fig. 1c and supplementary Tables 2 and 3 for details). However, participants from academic centers indicated more frequently to treat a high patient volume compared to participants from non-academic centers $(39 / 40$ [97.5\%] vs. $1 / 40$ [2.5\%], $p<0.001)$.

\section{Preoperative imaging in patients planned for neurosurgical resection of $\mathrm{BM}$}

Preoperative imaging was routinely performed by 114 / 120 (95.0\%) participating physicians and MRI was the most commonly applied preoperative imaging technique (112/120 [93.3\%], Table 2 and Fig. 2a and b). The use of routine preoperative imaging was comparable between academic and non-academic centers (84/89 [94.4\%] vs. 28/31 [90.3\%]; $p=0.435$, Fig. 2a), low- and high-patient volume centers $(69 / 71[97.2 \%]$ vs. $40 / 40[100 \%] ; p=$ 0.284, Fig. 2b) and European and non-European countries (88/93 [94.6\%] vs. 24/27 [88.9\%]; $p=0.293)$. Obtaining preoperative imaging was reported at comparable rates for neurosurgeons and participants with other specialty $(73 / 76[96.1 \%]$ vs. $39 / 44[88.6 \%] ; p=0.117)$. Combined preoperative imaging techniques using MRI, CT and/or PET were applied by 44/120 (36.6\%) physicians. The combination of MRI with CT was used more often compared to MRI and PET combination (27/120 [22.5\%] vs. $10 / 120[8.3 \%])$ or the triple combination of MRI, CT and PET (7/120 [5.8\%]).

\section{Intraoperative imaging and techniques to guide BM resection}

A total of 59/120 (49.1\%) physicians reported that intraoperative imaging during neurosurgical resection was conducted at their particular center. The most widely applied intraoperative imaging technique was intraoperative ultrasound (39/120 [32.5\%]) followed by intraoperative MRI or CT $(12 / 120$ [10.0\%]). Availability rate of intraoperative MRI or CT was comparable between academic and non-academic centers (9/12 [75.0\%] vs. 3/12 [25.0\%]; $p=0.945)$ or high and low patient volume centers $(7 / 11[63.6 \%]$ vs. $4 / 11[36.4 \%] ; p=0.981)$.

Intraoperative neuronavigation was the most frequently applied intraoperative technique for guidance of BM resection (90/120 [75.0\%]), followed by electrophysiological monitoring/stimulation (56/120 [46.7\%]), and awake surgery (42/120 [35.0\%]). 23/120 [19.2\%]) physicians indicated to use fluorescence-guided surgery with 5-aminolevulinic acid (5-ALA). The rate of fluorescence-guided surgery in non-academic centers was numerically higher $(8 / 31$ [25.8\%]) compared to academic centers $(15 / 89$ [16.9\%]; $p=0.202$; see Table 2$)$. 

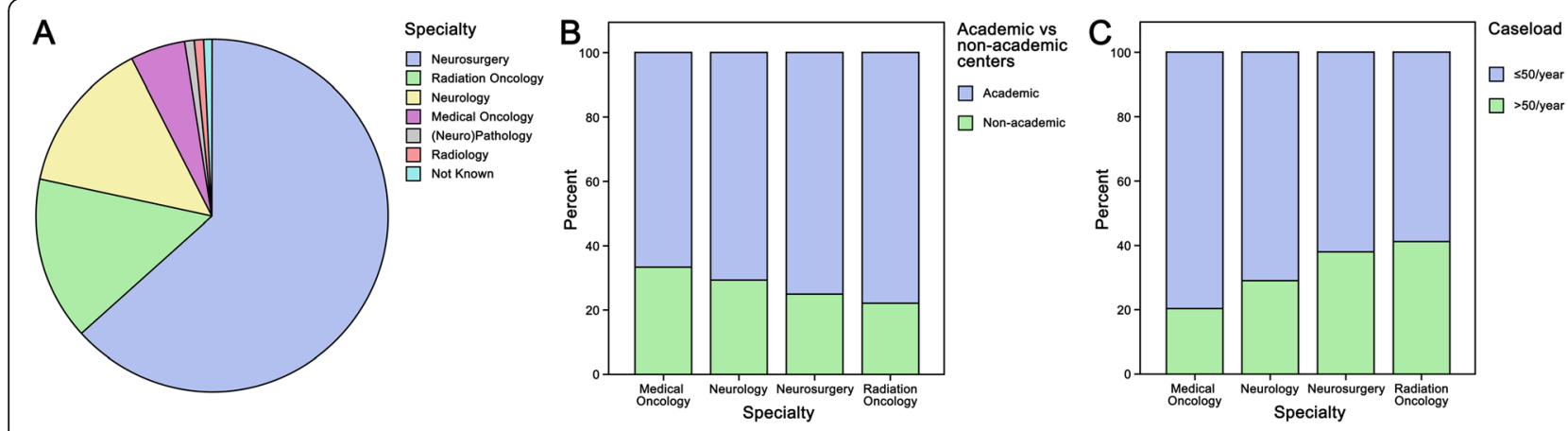

Fig. 1 a The distribution of the participants throughout the specialties showed the highest participation of neurosurgeons followed by radiation oncologists and neurologists with a similar distribution in $\mathbf{b}$ academic versus non-academic centers and $\mathbf{c}$ high versus low volume centers

\section{Postoperative imaging after neurosurgical BM resection} A total of $106 / 120$ (88.3\%) physicians reported to routinely perform postoperative imaging including MRI and/or CT within the first days after neurosurgical resection. The remaining 6 participants stated to perform no postoperative imaging $(5 / 120[4.2 \%])$ or were not aware of the routine practice at their center $(1 / 120$ [0.8\%]). 62/120 (51.7\%) participants indicated to perform postoperative MRI alone, 29/120 (24.2\%) to perform postoperative CT and the residual 15/120 (12.5\%) participants stated to prefer the combination of MRI and CT imaging (Fig. 3a and Table 3). Postoperative CT was performed to excluded postoperative complications such as hematoma or ischemia according to $29 / 120$ (24.2\%) participants. $10 / 120(8.3 \%)$ physicians indicated to perform a CT in the postoperative course to evaluate the extent of tumor resection. Medical oncologists (3/6 [50\%]) reported the need for a postoperative MRI less frequently compared to neurologists $(12 / 17$ [70.6\%]), radiation oncologists $(14 / 18[77.8 \%])$ and neurosurgeons (47/76 [61.8\%], $p=0.484$; Fig. 3a and b). Indication for postoperative MRI was given at comparable rates between participants from academic and non-academic centers (58/ 89 [65.2\%] vs. 19/31 [61.3\%], $p=0.698$; Fig. 3c) as well as from high and low patient volume centers (49/71 [69.0\%] vs 25/40 [62.5\%], $p=0.485$; Fig. 3d). Participants from European countries indicated the use of postoperative MRI more frequently compared to participants from non-European countries (64/93 [68.8\%] vs. 13/27 [48.1\%], $p=0.049)$.

Early postoperative MRI within $\leq 72 \mathrm{~h}$ after resection was indicated to be routinely performed by $73 / 120$ (60.8\%) physicians. The number of BM (26/120 [21.7\%]), histology of primary tumor (18/120 [15\%]), previous therapies (18/120 [15\%]) and the graded prognostic assessment class/life expectancy of patient (12/120 ([10\%]) were nominated parameters influencing the time point of postoperative MRI. Evaluating the extent of resection was the most commonly reported reason to perform a postoperative MRI (73/120 [60.8\%]). In case of residual tumor in the postoperative MRI, 32/120 (26.7\%) participants indicated to adjust the radiotherapy plan, 34/120 (28.3\%) to consider re-resection in order to achieve complete and 8/120 (6.7\%) stated to consider both.

No availability of postoperative MRI (13/120 [10.8\%]) or high costs $(9 / 120$ [7.5\%]) were the most frequent reasons to omit postoperative MRI.

Standard operating procedures for perioperative imaging Local standard operating procedures (SOP) on the perioperative imaging in BM patients were available for 94/ $120(78.3 \%)$ physicians (Table 2). No difference in the use of local SOP for perioperative imaging between participants from academic and non-academic centers (68/ 89 [76.4\%] vs. 26/31 [83.9\%]; $p=0.385)$, high and low patient volume centers (56/71 [78.9\%] vs. 35/40 [87.5\%]; $p=0.256)$ or European and non-European countries (73/93 [78.5\%] vs. 21/27 [77.8\%]; $p=0.937$ ) was evident.

\section{Availability of a dedicated neuro-oncology tumor board for BM patients}

Treatment plans for BM patients were discussed in a dedicated neuro-oncology tumor board by $98 / 120$ (81.7\%) participating physicians. Dedicated neurooncology tumor boards were established at comparable rates in academic and non-academic centers (73/89 [82.0\%] vs. $25 / 31$ [80.6\%]; $p=0.864)$, in high and low patient volume centers $(62 / 71$ [87.3\%] vs. $34 / 40$ [85\%]; $p=$ $0.731)$ and in European vs. non-European countries (77/ 93 [82.8\%] vs. $21 / 27$ [77.8\%]; $p=0.553)$. Both pre- as well as additional postoperative discussion of the individual cases were performed by 63/98 (64.2\%) physicians.

\section{Discussion}

Neurosurgical resection is an important treatment option in the multimodal management of BM patients [2]. Although BM represent the most common brain tumors, 
Table 2 Pre- and intraoperative imaging of patients treated with resection of $\mathrm{BM}$

\begin{tabular}{|c|c|c|}
\hline & $n$ & $\%$ \\
\hline \multicolumn{3}{|l|}{ Standards for perioperative imaging } \\
\hline Yes & 94 & 78.3 \\
\hline No & 14 & 11.7 \\
\hline Not known & 12 & 10.0 \\
\hline \multicolumn{3}{|l|}{ Imaging is supervised by ... } \\
\hline Neuroradiologist & 98 & 81.7 \\
\hline General radiologist & 12 & 10.0 \\
\hline Neurosurgeon & 1 & 0.8 \\
\hline Not known & 9 & 7.5 \\
\hline \multicolumn{3}{|l|}{ Type of preoperative imaging } \\
\hline MRI & 112 & 93.3 \\
\hline $\mathrm{CT}$ & 36 & 30.0 \\
\hline PET & 17 & 14.2 \\
\hline \multicolumn{3}{|l|}{ Multimodal preoperative imaging } \\
\hline MRI alone & 68 & 56.7 \\
\hline$M R I+C T$ & 27 & 22.5 \\
\hline$M R I+P E T$ & 10 & 8.3 \\
\hline$M R I+C T+P E T$ & 7 & 5.8 \\
\hline CT alone & 2 & 1.7 \\
\hline Not known & 6 & 5.0 \\
\hline \multicolumn{3}{|l|}{ Preoperative MRI protocol } \\
\hline Standard MRI protocol & 68 & 56.7 \\
\hline Advanced imaging protocol & 40 & 33.3 \\
\hline Shortened MRI protocol & 2 & 1.7 \\
\hline Not known & 10 & 8.3 \\
\hline \multicolumn{3}{|l|}{ Intraoperative techniques } \\
\hline Neuronavigation & 90 & 75.0 \\
\hline Electrophysiological monitoring/stimulation & 56 & 46.7 \\
\hline Awake surgery & 42 & 35.0 \\
\hline Intraoperative ultrasound & 39 & 32.5 \\
\hline Fluorescence-guided surgery & 23 & 19.2 \\
\hline Intraoperative MRI & 9 & 7.5 \\
\hline Intraoperative $\mathrm{CT}$ & 3 & 2.5 \\
\hline Not known & 11 & 9.2 \\
\hline
\end{tabular}

CT computed tomography, MRI magnetic resonance imaging, PET positron emission tomography

perioperative imaging guidelines for surgically treated BM to standardize optimal adjuvant treatment are so far lacking. The present survey conducted by the EANO Youngsters Committee is the first to evaluate the current perioperative imaging modalities in BM patients. A total of 120 physicians worldwide, from academic as well as non-academic centers, high and low volume centers, European and non-European countries, participated in this survey. The survey revealed that MRI is the preferred perioperative imaging technique and is routinely applied in the preoperative setting, whereas a high variability of postoperative neuroimaging routines (including CT and MRI) was observed throughout the EANO network.

MRI was the most commonly applied preoperative imaging technique, regardless of the investigated center and geographical localization. Preoperative MRI is a broadly established diagnostic tool to plan treatment options of BM including surgery, radiation therapy, radiosurgery and systemic treatments [2, 16, 19-23]. Differentiation of BM from other tumor entities, such as malignant gliomas or lymphomas, as well as pseudoprogression/radionecrosis, is predominately based on preoperative MRI $[16,20,21,23]$. Aside from diagnostic evaluation of presurgical MRI, this important tool also supports the neurosurgeon's approach to surgical planning [24-26]. Based on the experiences and recommendations for primary brain tumors, additional diffusion tensor imaging (DTI) can be applied in case of eloquent localizations also in BM patients in order to improve preoperative definition of the surgical strategy as well as subsequent intraoperative navigation to avoid injury of functional white matter tracts $[26,27]$. Nevertheless, the so far existing preoperative imaging recommendations from primary brain tumors would need validation in BM patients [28].

Neuronavigation was the most frequently applied intraoperative technique during BM resection, as it represents currently the standard for preoperative planning and intraoperative guidance [29-31]. Furthermore, electrophysiological monitoring/stimulation and awake surgery were used by some of the participating physicians. These techniques are useful to minimize the risk of a new postoperative neurological deficit and thus support the neurosurgeon to achieve safe resection of $\mathrm{BM}$ also in eloquent tumor localizations [32-34]. Moreover, one fourth of physicians reported to use fluorescence-guided surgery with 5-aminolevulinic-acid (5-ALA). To date, fluorescence-guided surgery is mainly used for resection of high-grade gliomas, but recently was also described to be useful for intraoperative visualization of BM tissue [7, 35-37]. Intraoperative MRI or CT were infrequently applied, potentially as a consequence of the high costs and the low acceptance in BM surgery. However, due to the frequent lack of clear delineation of BM towards the surrounding brain parenchyma intraoperative techniques and especially 5-ALA might be of additional value to ensure optimal extent of resection [6].

The majority of physicians performed a postsurgical MRI, although only approximately half of the participating physicians indicated to perform early postoperative MRI within $72 \mathrm{~h}$ after tumor resection. No differences in the use of postsurgical MRI were evident between 

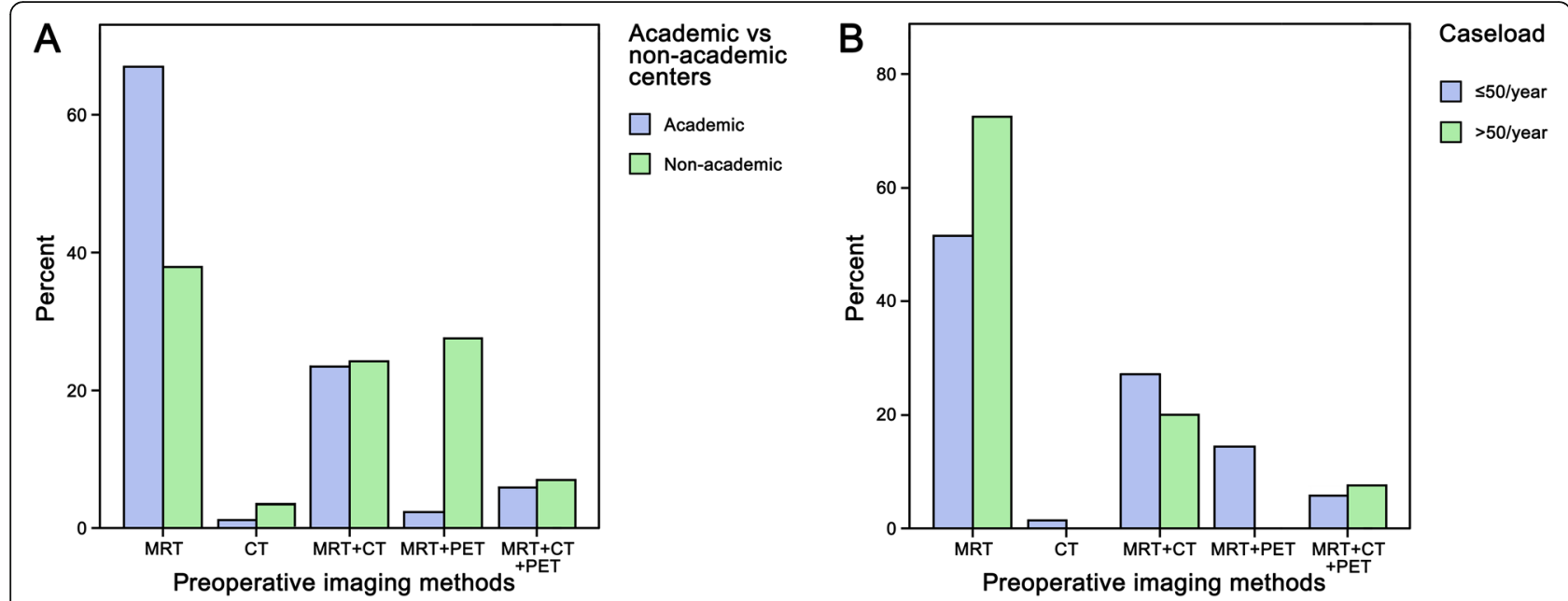

Fig. 2 Application of preoperative imaging methods revealed MRI as the most frequently applied preoperative method throughout (a) academic versus non-academic and (b) low versus high volume centers

academic and non-academic centers, while European participants reported the use more frequently than nonEuropean participants. Interestingly, differences were observed according to the medical specialties. Oncologists reported less frequent use of post-surgical imaging compared to the other specialties. EANO guidelines on diagnosis and treatment of $\mathrm{BM}$ recommend postoperative MRI to guide adjuvant radiotherapy applied to the resection cavity as the postsurgical resection cavity volume is smaller than preoperative BM volume [2]. However, no recommendation on the optimal timepoint for postoperative MRI after BM resection is given in the current version. As indeed timing is stated to be not relevant for this particular postoperative application [2]. Importantly, postsurgical changes, such as ischemia, bleeding, or postsurgical gliosis frequently occur and
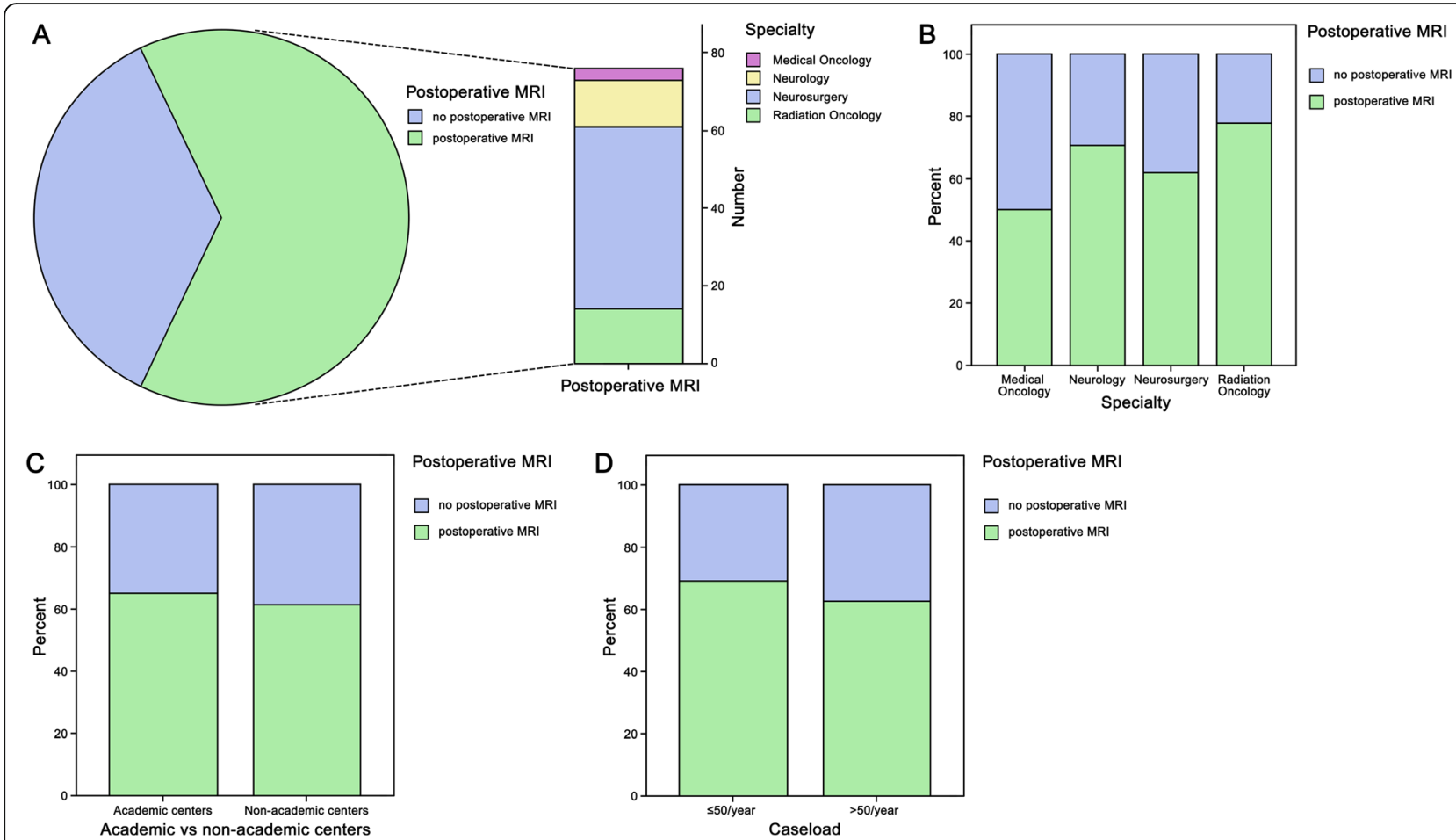

Fig. 3 a, b The application of postoperative MRI was more important for neurosurgeons followed by radiation oncologist and neurologists compared to medical oncologists. c Academic versus non-academic as well as $\mathbf{d}$ low and high volume centers equally performed MRI in the postoperative setting 
Table 3 Postoperative imaging of patients treated with resection of BM

\begin{tabular}{|c|c|c|}
\hline & $\mathrm{n}$ & $\%$ \\
\hline \multicolumn{3}{|l|}{ Postoperative imaging } \\
\hline Postoperative MRI & 77 & 64.2 \\
\hline Postoperative CT & 44 & 36.7 \\
\hline No postoperative imaging & 5 & 4.2 \\
\hline Not known & 1 & 0.8 \\
\hline \multicolumn{3}{|l|}{ Time point of postoperative MRI } \\
\hline$\leq 72 \mathrm{~h}$ after resection & 73 & 60.8 \\
\hline$>72 \mathrm{~h}$ to 7 days after resection & 2 & 1.7 \\
\hline$>7$ days to 4 weeks after resection & 7 & 5.8 \\
\hline$>4$ weeks to 3 months after resection & 18 & 15.0 \\
\hline$>3$ months after resection & 4 & 3.3 \\
\hline Very variable & 1 & 0.8 \\
\hline Not known & 15 & 12.6 \\
\hline \multicolumn{3}{|l|}{ Reasons for postoperative MRI } \\
\hline To evaluate the extent of resection & 73 & 60.8 \\
\hline To exclude postoperative complications (hematoma, ischemia ...) & 34 & 28.3 \\
\hline For research purpose & 8 & 6.7 \\
\hline \multicolumn{3}{|l|}{ Parameters influencing time point of postoperative MRI } \\
\hline Number of BM & 26 & 21.7 \\
\hline Histology of primary tumor & 18 & 15.0 \\
\hline Previous therapy of BM & 18 & 15.0 \\
\hline GPA class/life expectancy of patient & 12 & 10.0 \\
\hline None & 58 & 48.3 \\
\hline Not known & 4 & 3.3 \\
\hline \multicolumn{3}{|l|}{ Consequences in case of residual tumor } \\
\hline Adjustment of the radiotherapy plan & 32 & 26.7 \\
\hline Considering re-do surgery to achieve complete resection & 34 & 28.3 \\
\hline both & 8 & 6.7 \\
\hline \multicolumn{3}{|l|}{ Causes of lack of postoperative MRI } \\
\hline Considered unnecessary & 17 & 14.2 \\
\hline No capacity/availability & 13 & 10.8 \\
\hline Due to high costs & 9 & 7.5 \\
\hline Intraoperative MRI already performed & 0 & 0 \\
\hline
\end{tabular}

$B M$ brain metastases, $C T$ computed tomography, MRI magnetic resonance imaging

may mimic a residual tumor in case of MRI is performed later than $72 \mathrm{~h}$ after resection [8]. In glioma surgery, several guidelines stress the importance of an early postoperative MRI within $72 \mathrm{~h}$ after surgery to reliably differentiate postsurgical changes and residual tumor and guide the subsequent therapeutic approach [8]. A recent publication revealed residual tumor on early postoperative MRI in $20 \%$ of BM cases, although $92.3 \%$ of these were classified as complete resection by the surgeon [38]. These observations further stress the importance of accurately accessing the tumor residue with early postsurgical MRI and including this information in the further treatment plan.

More than half of the participants indicated to adjust the radiotherapy plan or even consider re-do surgery to achieve complete resection in case of residual tumor in the early postoperative MRI. Indeed, adjuvant therapy after BM resection has been controversially discussed. Whole brain radiotherapy (WBRT) has been shown to increase local tumor control as well as the distant brain control $[4,39,40]$. However, WBRT had no impact on overall survival $[4,39,40]$. Due to potential neuro- 
cognitive decline, WBRT is currently controversial in EANO guidelines [41, 42]. Adjuvant Stereotactic fractionated radiotherapy (SFRT) or stereotactic radiosurgery (SRS) of the resection cavity has been suggested to increase the local disease control [33,43]. So far only very small studies address the clinical impact of early postsurgical imaging in $\mathrm{BM}[38,44]$. One recent publication stressed that routine postoperative MRI is unnecessary because patients with small residual tumor did not undergo any changes of treatment plan [44]. In this retrospective study, the authors recommended postoperative imaging only in case of neurological deficits, concerns about large amounts of residual tumor or intraoperative complications [44]. However, considering the new opportunities of adjuvant SRS/SFRT, this might not hold true in modern BM management and should be investigated in further clinical trials.

The majority of participants of our survey stated to conduct perioperative imaging in BM according to local SOP. These findings were independent of academic vs. non-academic centers or European vs. non-European countries. Guidelines on the perioperative imaging are well established in primary brain tumors, but are missing so far for BM [8]. Especially in high-grade glioma patients, the evaluation of the extent of resection plays an important role for prognosis $[13,45]$. Several studies indicated a better progression-free and overall survival in case of complete resection of the contrast enhancing tumor $[13,45]$.

Based on the results of our survey, international guidelines for perioperative imaging in $\mathrm{BM}$ are warranted to ensure a standardized optimal postoperative treatment approach and to provide a comparable standard through centers. In our view, the most appropriate method of perioperative imaging in BM represents MRI. In this sense, we recommend performing a standardized preoperative MRI protocol for optimal tumor diagnosis, selection of the appropriate treatment option and preoperative planning. After surgery of BM, we suggest conducting a standardized early postsurgical MRI within $72 \mathrm{~h}$ after surgery to evaluate especially the extent of tumor resection and thus optimize subsequent treatment allocation. In case of a significant postsurgical residual tumor, we propose to consider a re-do surgery or adjustment of the radiotherapy plan.

Our survey was performed anonymously to reduce a potential bias based on reporting the treatment institution. However, in consequence we did not include the identification of the center and therefore cannot address how many participants from the same center answered the survey. Certainly, physicians with a particular focus on BM treatment were more likely to answer the survey out of interest and therefore bias the given results. Nevertheless, we provide the first investigation of the current practice of perioperative imaging in BM patients, showing a particular variability in the postoperative imaging modalities and therefore stressing the need for international guidelines to harmonize optimized perioperative treatment algorithms.

\section{Conclusion}

In conclusion, we were able to conduct the first international survey on perioperative imaging in BM patients. Although the majority of included physicians routinely use perioperative MRI, only half obtain early postoperative MRI to reliably identify residual tumor. No availability of postoperative MRI or high costs were the most frequent reasons to omit postoperative MRI. International guidelines on the perioperative imaging may help to optimize treatment approaches and ensure a high level of standard treatment throughout centers.

\section{Supplementary information}

Supplementary information accompanies this paper at https://doi.org/10. 1186/s12885-020-06897-z.

Additional file 1: Survey of the EANO Youngster - "Evaluation of perioperative management of surgically treated brain metastases".

Additional file 2: Supplementary Table 1. Specialization distribution within academic centers and non-academic centers. Supplementary Table 2. Specialization distribution within European and non-Europeancountries. Supplementary Table 3. Specialization distribution within high-volume and low-volume centers.

\section{Abbreviations}

5-ALA: 5-aminolevulinic acid; BM: Brain metastases; CT: Computed tomography; DTI: Diffusion tensor imaging; EANO: European Association of Neuro-Oncology; MRI: Magnetic resonance imaging; PET: Positron emission tomography; SFRT: Stereotactic fractionated radiotherapy; SOP: Standard operating procedures; SRS: Stereotactic radiosurgery; WBRT: Whole brain radiotherapy

\section{Acknowledgements}

We thank Michael Weller, Geoffrey Pilkington, Elizabeth Cohen-Jonathan Moyal, Roger Henriksson, Colin Watts, Roberta Rudà, Guido Reifenberger, Ingela Oberg and Jérôme Honnorat for the support, the approval and review of our survey.

We thank Ingrid Dobsak for graphical assistance.

Our results were presented at the EANO Meeting 2018 and SNO 2018 Annual Meeting.

\section{Authors' contributions}

BK: study design, data collection, data interpretation, manuscript writing, approval of final manuscript version. CMT: data collection, manuscript

writing, approval of final manuscript version. TW: data collection, manuscript writing, approval of final manuscript version. AJ: data collection, manuscript writing, approval of final manuscript version. AD: data collection, manuscript writing, approval of final manuscript version. AP: data collection, manuscript writing, approval of final manuscript version. JF: data collection, manuscript writing, approval of final manuscript version. JK: data collection, manuscript writing, approval of final manuscript version. CFF: data collection, manuscript writing, approval of final manuscript version. WW: data collection, manuscript writing, approval of final manuscript version. MP: study design, data collection, manuscript writing, approval of final manuscript version. GW: study design, data collection, manuscript writing, approval of final manuscript version. ASB: study design, data collection, data interpretation, manuscript writing, approval of final manuscript version. All authors have read and approved the manuscript. 


\section{Funding}

Funding was provided by the Medical University Vienna.

\section{Availability of data and materials}

The datasets used and/or analyzed during the current study are available from the corresponding author on request.

\section{Ethics approval and consent to participate}

This article contains human participants as respondent to the survey. The study was approved by the Ethic committee of the Medical University Vienna (EK 1614/2017) and written informed consent was given by all participants.

\section{Consent for publication}

All included figures are entirely unidentifiable and there are no details on individuals reported within the manuscript. The survey was performed completely anonymous.

\section{Competing interests}

All authors certify that they have no affiliations with or involvement in any organization or entity with any financial interest (such as honoraria; educational grants; participation in speakers' bureaus; membership, employment, consultancies, stock ownership, or other equity interest; and expert testimony or patent-licensing arrangements), or non-financial interest (such as personal or professional relationships, affiliations, knowledge or beliefs) in the subject matter or materials discussed in this manuscript. Anna Sophie Berghoff has research support from Daiichi Sankyo and honoraria for lectures, consultation or advisory board participation from Roche Bristol-Meyers Squibb, Merck, Daiichi Sankyo as well as travel support from Roche, Amgen and AbbVie.

Matthias Preusser has received honoraria for lectures, consultation or advisory board participation from the following for-profit companies: BristolMyers Squibb, Novartis, Gerson Lehrman Group (GLG), CMC Contrast, GlaxoSmithKline, Mundipharma, Roche, Astra Zeneca, AbbVie, Lilly, Medahead, Daiichi Sankyo, Merck Sharp \& Dome.

Amélie Darlix has received travel support from Roche, Amgen and Chugai. Christian F. Freyschlag received honoraria for lectures, consultation or advisory board participation from AbbVie, BrainLab, Novocure, proMed Instruments, Roche, Zeiss as well as travel support from Roche and Novocure.

All others indicate no conflicts of interests.

\section{Author details}

${ }^{1}$ Department of Neurosurgery, Medical University Vienna, Vienna, Austria.

${ }^{2}$ Comprehensive Cancer Center, Medical University of Vienna, Vienna, Austria. ${ }^{3}$ Clinical Cooperation Unit Neurooncology, German Cancer Consortium (DKTK), German Cancer Research Center (DKFZ), Heidelberg, Germany. ${ }^{4}$ Department of Neurology and Brain Tumor Center, University Hospital and University of Zurich, Zurich, Switzerland. ${ }^{5}$ Department of Neurosurgery, Sahlgrenska University Hospital, Gothenburg, Sweden. ${ }^{6}$ Department of Medical Oncology, Institut Régional Du Cancer Montpellier, University of Montpellier, Montpellier, France. ${ }^{7}$ Department of Neuro-Oncology, University and City of Health and Science Hospital of Turin, Turin, Italy. ${ }^{8}$ Department of Biomedical Imaging and Image-guided Therapy, Medical University Vienna, Vienna, Austria. ${ }^{9}$ Department of Neurosurgery, Medical University Innsbruck, Innsbruck, Austria. ${ }^{10}$ Neurology Clinic \& National Center for Tumor Disease, University of Heidelberg, Heidelberg, Germany. ${ }^{11}$ Department of Medicine I, Clinical Division of Oncology, Medical University of Vienna, Waehringer Guertel 18-20, 1090 Vienna, Austria.

\section{Received: 6 January 2020 Accepted: 23 April 2020}

Published online: 12 May 2020

\section{References}

1. Sperduto PW, Kased N, Roberge D, Xu Z, Shanley R, Luo X, Sneed PK, Chao ST, Weil RJ, Suh J, et al. Summary report on the graded prognostic assessment: an accurate and facile diagnosis-specific tool to estimate survival for patients with brain metastases. J Clin Oncol. 2012;30(4):419-25.

2. Soffietti R, Abacioglu U, Baumert B, Combs SE, Kinhult S, Kros JM, Marosi C, Metellus P, Radbruch A, Villa Freixa SS, et al. Diagnosis and treatment of brain metastases from solid tumors: guidelines from the European Association of Neuro-Oncology (EANO). Neuro-Oncology. 2017;19(2):162-74.

3. Patchell RA, Tibbs PA, Walsh JW, Dempsey RJ, Maruyama Y, Kryscio RJ, Markesbery WR, Macdonald JS, Young B. A randomized trial of surgery in the treatment of single metastases to the brain. N Engl J Med. 1990;322(8):494-500

4. Patchell RA, Tibbs PA, Regine WF, Dempsey RJ, Mohiuddin M, Kryscio RJ, Markesbery WR, Foon KA, Young B. Postoperative radiotherapy in the treatment of single metastases to the brain: a randomized trial. JAMA. 1998; 280(17):1485-9.

5. Neves S, Mazal PR, Wanschitz J, Rudnay AC, Drlicek M, Czech T, Wustinger C, Budka H. Pseudogliomatous growth pattern of anaplastic small cell carcinomas metastatic to the brain. Clin Neuropathol. 2001;20(1):38-42.

6. Berghoff AS, Rajky O, Winkler F, Bartsch R, Furtner J, Hainfellner JA, Goodman SL, Weller M, Schittenhelm J, Preusser M. Invasion patterns in brain metastases of solid cancers. Neuro-Oncology. 2013;15(12):1664-72.

7. Kamp MA, Fischer I, Buhner J, Turowski B, Cornelius JF, Steiger HJ, Rapp M, Slotty PJ, Sabel M. 5-ALA fluorescence of cerebral metastases and its impact for the local-in-brain progression. Oncotarget. 2016;7(41):66776-89.

8. Vogelbaum MA, Jost S, Aghi MK, Heimberger AB, Sampson JH, Wen PY, Macdonald DR, Van den Bent MJ, Chang SM. Application of novel response/ progression measures for surgically delivered therapies for gliomas: response assessment in Neuro-oncology (RANO) working group. Neurosurgery. 2012;70(1):234-43 discussion 243-234.

9. Weller M, van den Bent M, Hopkins K, Tonn JC, Stupp R, Falini A, CohenJonathan-Moyal E, Frappaz D, Henriksson R, Balana C, et al. EANO guideline for the diagnosis and treatment of anaplastic gliomas and glioblastoma. Lancet Oncol. 2014;15(9):e395-403.

10. Wen PY, Kesari S. Malignant gliomas in adults. N Engl J Med. 2008;359(5): 492-507.

11. Hervey-Jumper SL, Berger MS. Maximizing safe resection of low- and highgrade glioma. J Neuro-Oncol. 2016;130(2):269-82.

12. Keles GE, Chang EF, Lamborn KR, Tihan T, Chang CJ, Chang SM, Berger MS. Volumetric extent of resection and residual contrast enhancement on initial surgery as predictors of outcome in adult patients with hemispheric anaplastic astrocytoma. J Neurosurg. 2006;105(1):34-40.

13. Lacroix M, Abi-Said D, Fourney DR, Gokaslan ZL, Shi W, DeMonte F, Lang FF, McCutcheon IE, Hassenbusch SJ, Holland E, et al. A multivariate analysis of 416 patients with glioblastoma multiforme: prognosis, extent of resection, and survival. J Neurosurg. 2001;95(2):190-8.

14. Bloch O, Han SJ, Cha S, Sun MZ, Aghi MK, McDermott MW, Berger MS, Parsa AT. Impact of extent of resection for recurrent glioblastoma on overall survival: clinical article. J Neurosurg. 2012;117(6):1032-8.

15. Jakola AS, Skjulsvik AJ, Myrmel KS, Sjavik K, Unsgard G, Torp SH, Aaberg K, Berg T, Dai HY, Johnsen $K$, et al. Surgical resection versus watchful waiting in low-grade gliomas. Ann Oncol. 2017;28(8):1942-8.

16. Cha S. Neuroimaging in neuro-oncology. Neurotherapeutics. 2009;6(3):46577.

17. Thust SC, Heiland S, Falini A, Jager HR, Waldman AD, Sundgren PC, Godi C, Katsaros VK, Ramos A, Bargallo N, et al. Glioma imaging in Europe: a survey of 220 centres and recommendations for best clinical practice. Eur Radiol. 2018;28(8):3306-17.

18. Schucht P, Murek M, Jilch A, Seidel K, Hewer E, Wiest R, Raabe A, Beck J. Early re-do surgery for glioblastoma is a feasible and safe strategy to achieve complete resection of enhancing tumor. PLoS One. 2013;8(11): e79846.

19. Donahue BR, Goldberg JD, Golfinos JG, Knopp EA, Comiskey J, Rush SC, Han K, Mukhi V, Cooper JS. Importance of MR technique for stereotactic radiosurgery. Neuro-Oncology. 2003;5(4):268-74.

20. Pope WB. Brain metastases: neuroimaging. Handb Clin Neurol. 2018;149:89112

21. Nowosielski M, Radbruch $\mathrm{A}$. The emerging role of advanced neuroimaging techniques for brain metastases. Chin Clin Oncol. 2015:4(2):23.

22. Barajas RF Jr, Cha S. Imaging diagnosis of brain metastasis. Prog Neurol Surg. 2012;25:55-73.

23. Alexander BM, Brown PD, Ahluwalia MS, Aoyama H, Baumert BG, Chang SM, Gaspar LE, Kalkanis SN, Macdonald DR, Mehta MP, et al. Clinical trial design for local therapies for brain metastases: a guideline by the response assessment in Neuro-oncology brain metastases working group. Lancet Oncol. 2018;19(1):e33-42.

24. Sills AK. Current treatment approaches to surgery for brain metastases. Neurosurgery. 2005;57(5 Suppl):S24-32 discusssion S21-24. 
25. Haberland N, Ebmeier K, Hliscs R, Grnewald JP, Silbermann J, Steenbeck J, Nowak H, Kalff R. Neuronavigation in surgery of intracranial and spinal tumors. J Cancer Res Clin Oncol. 2000;126(9):529-41.

26. Leclercq D, Delmaire C, de Champfleur NM, Chiras J, Lehericy S. Diffusion tractography: methods, validation and applications in patients with neurosurgical lesions. Neurosurg Clin N Am. 2011;22(2):253-68 ix.

27. Nimsky C, Ganslandt O, Fahlbusch R. Implementation of fiber tract navigation. Neurosurgery. 2006;58(4 Suppl 2):ONS-292-303 discussion ONS 303-294

28. Conti Nibali M, Rossi M, Sciortino T, Riva M, Gay LG, Pessina F, Bello L. Preoperative surgical planning of glioma: limitations and reliability of fMRI and DTI tractography. J Neurosurg Sci. 2019;63(2):127-34.

29. Roberts DW, Strohbehn JW, Hatch JF, Murray W, Kettenberger H. A frameless stereotaxic integration of computerized tomographic imaging and the operating microscope. J Neurosurg. 1986;65(4):545-9.

30. Orringer DA, Golby A, Jolesz F. Neuronavigation in the surgical management of brain tumors: current and future trends. Expert Rev Med Devices. 2012;9(5):491-500

31. Willems PW, van der Sprenkel JW, Tulleken CA, Viergever MA, Taphoorn MJ. Neuronavigation and surgery of intracerebral tumours. J Neurol. 2006;253(9): 1123-36.

32. Obermueller T, Schaeffner M, Shiban E, Droese D, Negwer C, Meyer B, Ringel F, Krieg SM. Intraoperative neuromonitoring for function-guided resection differs for supratentorial motor eloquent gliomas and metastases. BMC Neurol. 2015;15:211.

33. Neuloh G, Pechstein U, Cedzich C, Schramm J. Motor evoked potential monitoring with supratentorial surgery. Neurosurgery. 2004;54(5):1061-70 discussion 1070-1062.

34. Krieg SM, Schaffner M, Shiban E, Droese D, Obermuller T, Gempt J, Meyer B, Ringel F. Reliability of intraoperative neurophysiological monitoring using motor evoked potentials during resection of metastases in motor-eloquent brain regions: clinical article. J Neurosurg. 2013;118(6):1269-78.

35. Kamp MA, Grosser P, Felsberg J, Slotty PJ, Steiger HJ, Reifenberger G, Sabel M. 5-aminolevulinic acid (5-ALA)-induced fluorescence in intracerebral metastases: a retrospective study. Acta Neurochir. 2012;154(2):223-8 discussion 228.

36. Widhalm G, Kiesel B, Woehrer A, Traub-Weidinger T, Preusser M, Marosi C, Prayer D, Hainfellner JA, Knosp E, Wolfsberger S. 5-Aminolevulinic acid induced fluorescence is a powerful intraoperative marker for precise histopathological grading of gliomas with non-significant contrastenhancement. PLoS One. 2013;8(10):e76988.

37. Stummer W, Pichlmeier U, Meinel T, Wiestler OD, Zanella F, Reulen HJ, Group AL-GS. Fluorescence-guided surgery with 5-aminolevulinic acid for resection of malignant glioma: a randomised controlled multicentre phase III trial. Lancet Oncol. 2006;7(5):392-401.

38. Kamp MA, Rapp M, Buhner J, Slotty PJ, Reichelt D, Sadat H, Dibue-Adjei M, Steiger HJ, Turowski B, Sabel M. Early postoperative magnet resonance tomography after resection of cerebral metastases. Acta Neurochir. 2015; 157(9):1573-80

39. Kocher M, Soffietti R, Abacioglu U, Villa S, Fauchon F, Baumert BG, Fariselli L, Tzuk-Shina T, Kortmann RD, Carrie C, et al. Adjuvant whole-brain radiotherapy versus observation after radiosurgery or surgical resection of one to three cerebral metastases: results of the EORTC 22952-26001 study. J Clin Oncol. 2011;29(2):134-41.

40. Brown PD, Ballman KV, Cerhan JH, Anderson SK, Carrero XW, Whitton AC, Greenspoon J, Parney IF, Laack NNI, Ashman JB, et al. Postoperative stereotactic radiosurgery compared with whole brain radiotherapy for resected metastatic brain disease (NCCTG N107C/CEC.3): a multicentre, randomised, controlled, phase 3 trial. Lancet Oncol. 2017;18(8):1049-60.

41. Chang EL, Wefel JS, Hess KR, Allen PK, Lang FF, Kornguth DG, Arbuckle RB, Swint JM, Shiu AS, Maor MH, et al. Neurocognition in patients with brain metastases treated with radiosurgery or radiosurgery plus whole-brain irradiation: a randomised controlled trial. Lancet Oncol. 2009;10(11):1037-44.

42. Soffietti R, Kocher M, Abacioglu UM, Villa S, Fauchon F, Baumert BG, Fariselli L, Tzuk-Shina T, Kortmann RD, Carrie C, et al. A European Organisation for Research and Treatment of Cancer phase III trial of adjuvant whole-brain radiotherapy versus observation in patients with one to three brain metastases from solid tumors after surgical resection or radiosurgery: quality-of-life results. J Clin Oncol. 2013;31(1):65-72.

43. Mahajan A, Ahmed S, McAleer MF, Weinberg JS, Li J, Brown P, Settle S, Prabhu SS, Lang FF, Levine N, et al. Post-operative stereotactic radiosurgery versus observation for completely resected brain metastases: a single-Centre, randomised, controlled, phase 3 trial. Lancet Oncol. 2017;18(8):1040-8.

44. Benveniste RJ, Ferraro N, Tsimpas A. Yield and utility of routine postoperative imaging after resection of brain metastases. J Neuro-Oncol. 2014;118(2):363-7.

45. Sanai N, Berger MS. Glioma extent of resection and its impact on patient outcome. Neurosurgery. 2008;62(4):753-64 discussion 264-756.

\section{Publisher's Note}

Springer Nature remains neutral with regard to jurisdictional claims in published maps and institutional affiliations.
Ready to submit your research? Choose BMC and benefit from:

- fast, convenient online submission

- thorough peer review by experienced researchers in your field

- rapid publication on acceptance

- support for research data, including large and complex data types

- gold Open Access which fosters wider collaboration and increased citations

- maximum visibility for your research: over $100 \mathrm{M}$ website views per year

At BMC, research is always in progress.

Learn more biomedcentral.com/submissions 